ISSN: 2162-3104 Print/ ISSN: 2166-3750 Online Volume 6, Issue 4 (2016), pp. 1062-1068 (C) Journal of International Students http://jistudents.org/

\title{
Food Identity and its Impact Upon the Study Abroad Experience
}

\author{
Andrea Ciliotta-Rubery \\ The College at Brockport, SUNY, USA
}

\begin{abstract}
Study Abroad programs go to great lengths to prepare students for living and working in environments unlike their own. While much of the preparation focuses on the challenges of university life, travel, safety and the like, this paper suggests that an early and thoughtful discussion of "food identity" will provide students with the tools necessary to become more insightful of the culture of their host country. Since eating is vital, regional foods provide a wonderful opportunity for entering into the culture of another. By exposing students to such factors as the malleable, political, gendered and deliberately constructed nature of food identities, students become more cognizant of the complex histories of other people and places, through the portal of their food.
\end{abstract}

Keywords: Food history, identity, gender; political ideology, study abroad

Educators involved with study abroad programs spend much time preparing students for the challenges of living, working and studying in other countries. While this process exposes them to the many ordinary difficulties of daily life, it does not fully provide them with the necessary ways to understand more deeply, the culture for which they have been newly thrusted. One way to remedy this void is to orient students to the food culture of their new home and more specifically, the food identity of its people and history. Undoubtedly, students go abroad for a variety of reasons and with variant levels of interest in their new found locations. What they do share in common, however, is their need to eat and thus, food becomes a more facile conduit for learning about and understanding the culture of their host countries. By exposing students to the idea of food identity, its changing nature, it historic connection to occupation, migration and trade, 
its use by political forces as a tool of manipulation and its revelations about gender, students will have a stronger and more mature appreciation of the history of their respective countries. In a world that presently faces great challenges in terms of ideological, religious and cultural differences, such a learning outcome may prove invaluable to the students' educational experience.

\section{PAST STUDIES AND DISCUSSION}

Most scholars agree that there has always been an association made between food and the cultures of different people, especially within anthropological studies. However, the concept of "food identity" as a separate and unique entity becomes fully developed in the 1980's when amongst social scientists "...,the notion of identity was taken up, to which food was directly and intimately linked” in a way that looked at food's “...classification and consumption, but also the preparation, the organization, the taboos, the company, the location, the pleasure, the time, the language, the symbols, the representation, the form, the meaning and the art of eating and drinking” (Scholliers, 2001, p. 7). As the food historian Massimo Montanari concludes:

Like spoken language, the food system contains and conveys the culture of its practitioner; it is the repository of traditions and of collective identity. It is therefore an extraordinary vehicle of selfrepresentation and of cultural exchange - a means of establishing identity to be sure, but also the first way of entering into contact with a different culture... (Montanari, 2006, p. 133).

How then can we use food, and in particular, food identity as a reliable port of entry for our students' understanding of another culture? The answer lies with the recognition of several important factors inherent to the essence of all food identities; namely, their malleable nature, their creation by internal and external forces, their use as a means of political manipulation, and their association with gender identity. While these four factors are certainly not the only dimensions contributing to food identity, they serve to express concepts that are both familiar and accessible to students. For this reason, an early "pre-departure" discussion of these four factors can help equip our students with the necessary tools for a more sophisticated understanding of food identities, as well as a greater appreciation for the way in which food reflects the historic evolutions of peoples and places. Such an outcome will likely enhance our students' journey towards becoming more responsible world citizens. 


\section{The Malleable Nature of Food Identities}

First, students must come to appreciate the adaptive nature of all food identities in response to changing circumstance. Through contact with other peoples and cultures, whether by trade, good political relations, migration, occupation or military defeat, food identities change in ways that reflect these new associations. John Dickie's Delizia, a comprehensive work on the food identities of Italian city states, provides ample examples to prove this point. Regarding food changes by occupiers and conquerors, he notes that many are surprised by the seemingly "un-Italian" nature of a food like couscous which appears in the Sicilian diet but is often thought of as a food from the Middle East. As Dickie notes, its presence dates back to Muslim control of the island during the 9-11th centuries and has since been long blended as part of the Sicilian diet (Dickie, 2008, pp. 15-16).

Similarly, traditional eating habits of the Romans included staples of bread, oil, wine and small birds but soon adapted to include larger, roasted game meats, upon Germanic conquest of the Empire. In both examples, food identities changed to reflect the new cultural influences of their occupiers, as the seamless adoption of various food habits bore witness to an early example of globalization.

\section{The Internal and External Creation of Food Identities}

Given the malleable nature of food identities, it seems reasonable for states to attempt to shape their own in a way that projects a desired image of its people, culture and history. This effort can be seen as an "internal" creation of a food identity. History provides examples of this when a city or state develops a unique and noteworthy food product, symbolic of regional pride. This can be seen in the 14th century, with the city of Parma and its creation of a most extraordinary regional cheese. Noted for its unique texture and flavor, its undisputed value could be seen in the many attempts by others to copy it! (Dickie, 2008, p. 31) Nonetheless, citizens of Parma took great pride in being able to identity its own "parmesan" cheese by its appearance and taste, and protecting it by uncovering all impostors seeking gain in the market. Ultimately, what began long ago as a source of regional pride, insisting upon authenticity of city and creative process, can now be seen with the modern "Denomination of Protected Status (DOP)" labeling, which provides product protection under the law (Dickie, 2008, p. 31). Such regulation is meant to recognize and safeguard the place of origin of these food products, along with the historic traditions involved in their creation. This same phenomenon can be seen with the proprietary regional control over the production of the champagne, which allows only sparkling wine made in the region of 
Champagne, to be called "champagne." The French have gone to great lengths to legally ensure that the Italians and the Spanish label their sparkling wines "prosecco" and "cava," respectively and that Champagne is always and only associated with Champagne, France!

While many of these early "internal" efforts to effectively protect and advance the reputation of a food product have continued today, not all places have had the luxury of internally developing and protecting their food identity. On the contrary, many places have had an "external" identity imposed upon them by others. As Dickie notes, these imposed identities are often uncomplimentary and difficult to remedy. One of the most striking examples of an imposed negative food identity can be found in the food history of the Neapolitan people. During the 19th century, Naples suffered from a reputation of being a dirty, disease ridden city. Its infamous "lazzari" street people were reputed to be filthy, slovenly and commonly seen eating the dirty street food of macaroni with their hands (2008, p. 150). This unseemly sight prompted the derogatory label of "maccheroni eaters" (2008, p. 151). Unfortunately, foreign visitors and some Neapolitans writers did much to enhance this reputation. In a work entitled The Bowels of Naples, Neapolitan native Matilde Serao describes Naples's other street food, pizza, as “...made from a dense dough that burns but does not cook, and is loaded with almost raw tomatoes, garlic, pepper and oregano,...” which when sold, "...the boy will stay there almost all day, while his pizza slices freeze in the cold, or turn yellow in the sun as the flies eat them" (Dickie, 2008, p. 189). This unappetizing image is matched by an 1877 Tuscan writer's commentary on Neapolitan people and their food habits: “...If they were left alone to roll around in their own filth, and given cheap snails and maccheroni to eat, then they will never ask what kind of government is running their country" (Dickie, 2008, p. 192). Ironically, overt attempts were made to remedy this negative food identity with the likes of a visit by Queen Margherita of Italy, whose arrival was meant to send a message that the city's food was safe and its streets free of cholera. As legend purports, she tried three different versions of a pizza and liked best the one with tomatoes, mozzarella and basil, since labeled pizza Margherita! (Dickie, 2008, p.186) While some remain suspect of the origins of this story and the supposed letter of appreciation sent by the Queen to Pizzeria Brandi, it serves to reinforce the lasting power of negatively imposed food identities upon cities and peoples and the great efforts made to remedy these unfavorable reputations.

\section{Food Identity as a Political Tool}

Throughout history, political entities have made deliberate attempts to shape food identities in ways that promote a desired message or image of 
the state. This is best demonstrated with the example of Mussolini and Fascist Italy. In 1925, Mussolini made a proclamation called "The Battle of the Grain," by which he encouraged Italians to be fully self-sufficient and reliant on Italian grown grains. With the exclamation "Italians, Love Bread," Mussolini attempted to reshape the Italian food identity away from any food source that was not locally grown or produced, in order to reassert Fascist strength and autonomy (Dickie, 2008, p. 244). Great effort was made through national campaigns to propagandize Italian love of vegetables and not meat, with a preference for all things lean and simplistic. Ironically, this message was designed to cover up the vast food shortages throughout Italy, suggesting instead that the Fascist man needs less to eat and thus, prefers a more austere diet!

The Germans chose a slightly different tactic with their grain shortages in WWII. Instead of suggesting that Nazi soldiers were of such a superior bodily constitution that they required less food, like the Italians, the Germans opted to launch a propaganda campaign that exalted the virtues of rye grains over wheat. Under the guidance of the Ministry of Agriculture, posters were put up throughout the country proclaiming "Eat rye bread. Color is not nourishment. Rye bread makes cheeks red" (Jacob, 2007, p. 363). Better health would be the promise made to deflect attention away from domestic and imported wheat shortages. Interestingly, after the war, when all things German were associated with ruin and death, a different attempt was made to manipulate the public perception of German food. Instead of promoting traditional foods that were in good supply, attempts were made to change the outward appearance of German food and project instead, a food identity that was part of a global community. In an article entitled, "Promise of More. The Rhetoric of (Food) Consumption in a Society Searching for Itself: West Germany in the 1950s," Michael Wildt argues that in an effort to "internationalize" its recipes and become part of "a family of nations," Germany set out to rename many of its traditional foods in an effort to disassociate them from a German past (Wildt, 2001, pp.69-70). Wildt notes that traditional cabbage became "Swiss cabbage," with diced meat dishes now being called "Portuguese meatballs" or "steak a la Lyonnaise" (2001, p. 69). These efforts were all done to reshape the German food identity in a way that would not remind those eating its food of Germany's recent past.

\section{Food and Gender Identity}

It will not come as a surprise to many people, including our students, that food has always had some association with gender. In fact, many may not be surprised to know that much of "feeding work," like the planning, acquiring, preparing, cooking and serving of food is still largely 
done by women throughout the world (Guptill, Copelton and Lucal, 2013, p. 31). However, what may be of some surprise is how closely linked the feeding work of women is connected to their identity. By this, food and all that its production entails, becomes a source of self-worth and value for many women of various cultures. Recognizing this connection is imperative to understanding and appreciating the essential way in which food work shapes the identity of women, across time and place. Without such an appreciation, our students may walk away with an inadequate understanding of a foundational element of their host country's essence.

A subtle way to expose students to this connection of gender and food identity is through the short stories of Jumpa Lahiri's The Interpreter of Maladies. These extraordinary stories of family love, loss and personal disconnect provide students with a lasting sense of how food plays a supportive and defining role for women within Indian culture. No story demonstrates this better than "Mrs. Sen's," the story of a young professor and his wife who comes to the United States for Mr. Sen's newly acquired appointment in a mathematics department. While Mr. Sen views this opportunity with excitement and purpose, Mrs. Sen feels dislocated, uncertain in her new role as a wife in America. This becomes painfully apparent to the reader when Mrs. Sen interacts with the mother of Eliot, the young boy she watches after school. Unlike Mrs. Sen, Eliot's mom is a single-mom who works full-time and dedicates little time to cooking. Mrs. Sen, on the other hand, goes to great length preparing food for both her husband and Eliot, paying special attention to the quality of the utensils and ingredients used in its preparation. Nostalgically, Mrs. Sen tells Eliot that in her homeland, whenever there is a special occasion, women gather and spend the whole night preparing food with their special blades, talking and laughing with each other. Her value as a wife manifests itself with an ordered house, a loving family and meticulously prepared foods. No such equivalent seemed to exist here. What Eliot's mom viewed as "...so much trouble," Mrs. Sen saw as "No trouble at all” (Lahiri, 1999, p.118). In a new land that seemed to value little of what she did, Mrs. Sen was lost. Directing the attention of our students to stories like these will help facilitate a greater understanding and sensitivity to the many cultural variations associated with food identity and gender, especially those that show little similarity to their own.

\section{CONCLUSION}

It is important for our students to remember that as they travel, they will be invited to participate and share in the meals of others. In doing so, they must recognize that with each of these invitations, comes an opportunity for a deeper understanding of the people and places for which they are guests. 
Taking advantage of such an opportunity requires our students to recognize that the food identity of each culture is in part, the product of its geographic location, political and social history, and all corresponding class, religious and gender distinctions that constitute the long narrative of a people. In recognizing these factors, our students are likely to come away from their study abroad experience with a more comprehensive understanding of their host country. By familiarizing themselves with some basic facts about food identity, our students will be provided with an invaluable tool set that will allow them to understand better the rich and complex nature of a place through the portal of its food.

\section{REFERENCES}

Counihan, C., \& Van Esterik, P. (2013). Food and culture: A reader. New York, NY: Routledge.

Dickie, J. (2008). Delizia!: The epic history of the Italians and their food. New York, NY: Free Press.

Fischler, C. (1988). Food, self and identity. Social Science Information, 27, 275293.

Guptill, A. E., Copelton, D.A., \& Lucal, B. (2013). Food and society: Principles and paradoxes. Cambridge, MA: Polity.

Jacob, H. E., Winston, R., \& Winston, C. (2007). Six thousand years of bread: Its holy and unholy history. New York: Skyhorse Publishing.

Lahiri,J. (1999). Interpreter of Maladies. Boston, MA: Mariner Books.

Long, L. (ed.) (2004) Culinary tourism. Lexington, KY: U of K Press.

Montanari, M. (2006). Food is culture. New York, NY: Columbia University Press.

Scholliers, P. (2001). Food, drink and identity: Cooking, eating and drinking in Europe since the Middle Ages. Oxford, England: Berg.

Wildt, M. (2001). Promise of More. The rhetoric of (food) consumption in a society searching for itself: West Germany in the 1950's. In Food, drink and identity: Cooking, eating and drinking in Europe since the Middle Ages. (pp. 63-80). Oxford, England: Berg.

ANDDREA CILIOTTA-RUBERY, $\mathrm{PhD}$, is a Professor of political science and international studies, with a focus on medieval political thought. She is the author of several articles and book chapters, on such topics as Machiavelli, Shakespeare, $16^{\text {th }}$ century politics and literature, the political novel, Turgenev, Aristotle and political extremism. She is the recipient of the Chancellor's Award for Excellence in Teaching and participates in various study abroad experiences with Brockport students.

Email: arubery@brockport.edu 